\title{
Dynamic Mechanical Analysis and Three-Body Abrasive Wear Behaviour of Thermoplastic Copolyester Elastomer Composites
}

\author{
Hemanth Rajashekaraiah, ${ }^{1}$ Sekar Mohan, ${ }^{1}$ Pramoda Kumari Pallathadka, ${ }^{2}$ \\ and Suresha Bhimappa ${ }^{3}$ \\ ${ }^{1}$ Karunya School of Mechanical Sciences, Karunya University, Coimbatore 641 114, India \\ ${ }^{2}$ Institute of Materials Research and Engineering, A* STAR (Agency for Science, Technology and Research), \\ 3 Research Link, Singapore 117602 \\ ${ }^{3}$ Department of Mechanical Engineering, The National Institute of Engineering, Mysore 570 008, India
}

Correspondence should be addressed to Suresha Bhimappa; sureshab2004@yahoo.co.in

Received 30 May 2014; Revised 4 August 2014; Accepted 26 August 2014; Published 19 November 2014

Academic Editor: Huseyin Çimenoğlu

Copyright (c) 2014 Hemanth Rajashekaraiah et al. This is an open access article distributed under the Creative Commons Attribution License, which permits unrestricted use, distribution, and reproduction in any medium, provided the original work is properly cited.

\begin{abstract}
Various amounts of short fibers (glass and carbon) and particulate fillers like polytetrafluoroethylene (PTFE), silicon carbide (SiC), and alumina $\left(\mathrm{Al}_{2} \mathrm{O}_{3}\right)$ were systematically introduced into the thermoplastic copolyester elastomer (TCE) matrix for reinforcement purpose. The mechanical properties such as storage modulus, loss modulus, and Tan $\delta$ by dynamic mechanical analysis (DMA) and three-body abrasive wear performance on a dry sand rubber wheel abrasion tester have been investigated. For abrasive wear study, the experiments were planned according to $L_{27}$ orthogonal array by considering three factors and three levels. The complex moduli for TCE hybrid composites were pushed to a higher level relative to the TCE filled PTFE composite. At lower temperatures (in the glassy region), the storage modulus increases with increase in wt.\% of reinforcement (fiber + fillers) and the value is maximum for the composite with $40 \mathrm{wt} . \%$ reinforcement. The loss modulus and damping peaks were also found to be higher by the incorporation of $\mathrm{SiC}$ and $\mathrm{Al}_{2} \mathrm{O}_{3}$ microfillers. The routine abrasive wear test results indicated that TCE filled PTFE composite exhibited better abrasion resistance. Improvements in the abrasion resistance, however, have not been achieved by short-fiber and particlaute filler reinforcements. From the Taguchi's experimental findings, optimal combination of control factors were obtained for minimum wear volume and also predictive correlations were proposed. Further, the worn surface morphology of the samples was discussed.
\end{abstract}

\section{Introduction}

In recent times, there has been a remarkable growth in large scale production of fiber and/or filler-reinforced thermoplastic polymer matrix composites for engineering applications. Engineering polymers and polymer reinforced with fibers and particulate fillers are widely used in design. Polymer composites are often required to move in contact with hard abrasive particles as counterface. Some practical situations are sleeve bearings, marine stern bearings, pipe and chute liners used to transport abrasive materials, rotor and powder mixers, blades and components in agricultural and earth moving equipment, and impellers in pumps handling industrial fluids [1]. In general, it is the mechanical load carrying capacity and specific wear rate of the composites that determine their acceptability in practical applications. Different types and amounts of fiber reinforcement and/inorganic fillers are known to improve many physical and/or mechanical properties of polymers, and their potential in improving the abrasive wear resistance is worth discovering [2]. Abrasive wear is the most important among all the forms of wear because it contributes almost $64 \%$ of the total cost of the wear [3]. It is caused due to hard particles or hard protuberances that are forced against and move along a solid surface [4].

Several researchers have observed the significant changes in the mechanical properties like storage and loss moduli and $\operatorname{Tan} \delta$ of polymers reinforced with fibers and particulate fillers [5-10]. Jin et al. [5] conducted the study on dynamic 
mechanical analysis (DMA) of multiprocessed multiwalled carbon nanotube/polymethylmethacrylate (PMMA) composites to determine storage and loss moduli and Tan $\delta$. Hassan et al. [6] investigated the dynamic mechanical property of injection moulded glass fiber/polyamide 66 (PA66) composite. They determined the Tan $\delta$ of the virgin and filled material under dry and $50 \%$ relative humidity $(\mathrm{RH})$ and wet condition. Huang et al. [7] reported the modulus of polytetrafluoroethylene (PTFE) filled silica composites and concluded that increase in silica content in the composite reduces the modulus. However they have not reported the three-body abrasive wear behaviour in the study. Suresha et al. [8] investigated the effect of organomodified montmoril-lonite (oMMT) content in different wt.\% filled with epoxy nanocomposites on glass transition temperature $\left(T_{q}\right)$, storage and loss moduli and Tan $\delta$ along with three-body abrasive wear tests. They concluded that the $T_{g}$, storage, and loss moduli were decreased with increasing of oMMT filler loading. However, higher oMMT filler addition has shown minimum wear volume loss and improved mechanical properties. Thongsang et al. [9] studied the dynamic mechanical and tribological properties of fly ash silica (FASi)/precipitated silica (PSi) filled natural rubber (NR) composites by varying the total silica contents in hybrid NR composites. They concluded that a 75\% PSi fraction to be introduced into FASi/PSi-filled NR compounds in order to achieve optimal mechanical properties and wear resistance. However the above investigations have not reported the relationship between the dynamic mechanical properties and wear resistance of the composites. Brostow et al. [10] demonstrated a link between dynamic mechanical properties and scratch/wear resistance on various thermoplastics like polycarbonate (PC), polypropylene (PP), polystyrene (PS), PTFE, styreneacrylonitrile (SAN), acrylonitrilebutadienestyrene (ABS), santoprene, surlyn, polyethersulfone (PES), and low density polyethylene (LDPE), when plotting Tan $\delta$ as a function of penetration depth or residual depth, a parabolic dependence is observed. However, a clear relationship with storage and loss moduli has not been found.

A number of studies on polymers and their composites subjected to abrasive wear have been reported [11-32] in literature. Budinski [11] investigated abrasion resistance of twenty one types of polymers and reported polyurethane having better abrasion resistance over other polymers. Briscoe et al. [12] reported abrasive wear of polyetheretherketone (PEEK) filled PTFE and PTFE filled PEEK. Sole and Ball [13] investigated the effect of fillers such as $\mathrm{CaCO}_{3}, \mathrm{BaSO}_{4}$, and fly ash on abrasive wear behaviour of PP. They reported that the addition of mineral fillers to the PP matrix decreases the wear resistance under severe abrasion conditions. Liu et al. [14] reported the abrasion resistance of ultrahigh molecular weight polyethylene (UHMWPE) with and without quartz particles as reinforcement under three-body abrasion conditions. Three-body abrasive wear of polymer based composites [15-21] has been extensively studied and considerable progress has been made in understanding the complex tribological process. Many researchers have reported that, the abrasive resistance of polymeric materials depends upon the intrinsic mechanical properties of the materials as well as on the test method used $[17,18]$.
It is well known that, by the addition of fillers or fibre reinforcement into most of the thermoplastic composites will improve the mechanical properties, however the same does not augment the wear resistance if the wear mechanisms are highly abrasive in nature [21]. However the findings of Bahadur et al. [22-27] revealed that the wear rate was considerably reduced by the addition of $\mathrm{CuO}$ and $\mathrm{CuS}$ to PTFE, $\mathrm{CuS}, \mathrm{CuF}_{2}, \mathrm{CaO}$, and $\mathrm{PbS}$ to Nylon 11 , and $\mathrm{CuO}, \mathrm{CuS}$, and $\mathrm{CuF}_{2}$ to PEEK. Contrary to the above observations, they also found that wear rate increased when the polymers were filled with particulate materials such as $\mathrm{BaF}_{2}, \mathrm{CaF}_{2}, \mathrm{ZnF}_{2}$, $\mathrm{SnF}_{2}, \mathrm{ZnS}, \mathrm{SnS}, \mathrm{ZnO}$, and $\mathrm{SnO}[22,26]$. Ravi Kumar et al. [28] conducted three-body abrasive wear behavior on PA66/PP blend and nanoclay (NC) + short carbon fiber (SCF) filled PA66/PP. They found that PA66/PP with NC + SCF exhibited highest wear rate than that of PA66/PP blend. Bijwe et al. [29] examined the neat polyetherimide (PEI), PEI filled with SGF and PTFE, molybdenum disulphide $\left(\mathrm{MoS}_{2}\right)$, and graphite in various wear modes. They reported that neat PEI exhibits better resistance under three-body abrasion. These findings have revealed that the fibers and fillers are detrimental for three-body abrasive wear behaviour and are in good agreement with the above listed findings [21, 22, 26].

Pettarin et al. [30] reported the wear behavior of high molecular weight high density polyethylene (HMWHDPE)/ $\mathrm{MoS}_{2}$ composites under dry sliding and abrasive wear conditions. They concluded that, incorporation of $\mathrm{MoS}_{2}$ to HMWHDPE improves its sliding and abrasive wear performance with a content of $\mathrm{MoS}_{2}$ for minimum wear rate around $10 \mathrm{wt} . \%$. Tong et al. [31] found that the coefficient of friction of UHMWPE was increased with the addition of wallastonite fibers, while the wear resistance of the composites was the highest when the fiber content was about $10 \mathrm{wt} . \%$. Voss and Friedrich [32] studied the sliding and abrasive wear behavior of short glass and carbon fiber reinforced PEEK composites at room temperature. They concluded that, the addition of SGF to PEEK showed marginal improvement in the abrasion resistance. The latter investigated reports [30-32] revealed that the incorporation of some type of fibers and fillers had improved the abrasion wear resistance of the polymer composites. These findings are in good agreement with the earlier investigation reports [22-27]. The above findings are in contrary, which had made the researchers to investigate the synergistic effect of the fibers and fillers on tribomechanical performances of the newly designed polymer based composites.

Design of experiment (DOE) is a technique to obtain the maximum amount of conclusive information from the minimum amount of work, time, energy, or other limited resources [33]. Taguchi's DOE approach has produced a unique and powerful quality improvement discipline that differs from the traditional process. It has been successfully applied for parametric appraisal in dry sliding wear study of polymer composites [34-37]. Ramesh and Suresha [37] investigated the optimization of tribological parameters in abrasive wear mode of carbon-epoxy (C-E) hybrid composites. They implemented Taguchi's DOE, Analysis of Variance (ANOVA) to determine the significance of control factors influencing wear and grey relational grade (GRG) to optimize the tribological 
TABLE 1: Source and supplier details of materials used in the present investigation.

\begin{tabular}{lcc}
\hline Polymer/filler & Designation & Source and supplier \\
\hline Thermoplastic copolyester elastomer & $\mathrm{TCE}$ & DSM and M/s Gargi Enterprises, Bangalore. \\
Polytetrafluoroethylene & $\mathrm{PTFE}$ & Du Pont Co. Ltd. \\
Short glass fibre & $\mathrm{SGF}$ & Fine Organics, Mumbai \\
Short carbon fibre & $\mathrm{SCF}$ & Fine Organics, Mumbai \\
Silicon carbide & $\mathrm{SiC}$ & Carborundum Universal Ltd, Chennai, India. \\
Alumina & $\mathrm{Al}_{2} \mathrm{O}_{3}$ & Triveni Chemicals, Gujarat, India. \\
\hline
\end{tabular}

TABLE 2: Mechanical properties of TCE + PTFE filled hybrid composites.

\begin{tabular}{|c|c|c|c|c|c|c|}
\hline Sl. number & $\begin{array}{c}\text { Matrix } \\
\text { material } \\
\text { (wt.\%) }\end{array}$ & Fiber (wt.\%) & Filler (wt.\%) & $\begin{array}{c}\text { Hardness }(H) \\
\quad(\text { Shore D) }\end{array}$ & $\begin{array}{c}\text { Tensile } \\
\text { strength }(S) \\
(\mathrm{MPa})\end{array}$ & $\begin{array}{c}\text { Tensile } \\
\text { elongation }(e \\
(\%)\end{array}$ \\
\hline 1 & TCE (85) & - & PTFE (15) & 60.8 & 30.58 & 18.9 \\
\hline 2 & TCE (68) & SGF (20) & PTFE (12) & 72.8 & 57.84 & 16.36 \\
\hline 3 & TCE $(60)$ & SGF (17.5) + SCF (2.5) & $\operatorname{PTFE}(10)+\mathrm{SiC}(5)+\mathrm{Al}_{2} \mathrm{O}_{3}(5)$ & 69.7 & 30.16 & 9.87 \\
\hline
\end{tabular}

parameters having multiple response. They concluded that filler loading and abrasive particle size have more significant effect on the specific wear rate of the composite and are therefore ranked first and second.

Efforts have been made by researchers to understand the dynamic mechanical characteristics and abrasive wear behaviour of the polymer based composites.

From the above discussion, it is obvious that the mechanical properties and tribological behaviour of thermoplastic blend system is significantly affected by fibers and fillers. Moreover, the abrasive wear performance of thermoplastics is very poor with the addition of fibers and or fillers. The mechanism that leads to the poor abrasion performance of thermoplastic composites has not been fully understood yet. Attempts to reinforce both fibers and fillers into thermoplastic copolyester elastomer (TCE) + polytetrafluoroethylene (PTFE) composite have not been reported so far. TCE as matrix and PTFE, $\mathrm{SiC}$, and $\mathrm{Al}_{2} \mathrm{O}_{3}$ fillers are good choice since for bearing applications both high modulus and high strength are desirable. Hence, in the present research article, TCE + PTFE composite with short fibers and fillers have been taken up for investigation with the intention of characterizing them for their dynamic mechanical analysis and three-body abrasive wear mode.

\section{Experimental Details}

2.1. Materials. Thermoplastic copolyester elastomer (TCE), commercially available as Arnitel EM 740 in the form of granules is the matrix material in the present investigation. Short E-glass fiber (SGF) was selected as reinforcement. Polytetrafluoroethylene (PTFE), short carbon fiber (SCF), silicon carbide $(\mathrm{SiC})$, and alumina $\left(\mathrm{Al}_{2} \mathrm{O}_{3}\right)$ were selected as micronscale fillers. The average diameter of the SGFs was approximately $12 \mu \mathrm{m}$ with an average fiber length of about $4 \mathrm{~mm}$. The average diameter of SCFs was approximately $7 \mu \mathrm{m}$ with an average fiber length of about $100 \mu \mathrm{m}$. The particle size of PTFE was about $5 \mu \mathrm{m}$ and around 5 to $10 \mu \mathrm{m}$ for $\mathrm{SiC}$ and $\mathrm{Al}_{2} \mathrm{O}_{3}$. The sources and suppliers of these materials are listed in Table 1.

2.2. Preparation of TCE Composites. The polymer granules and fillers were dried at $75^{\circ} \mathrm{C}$ for $10 \mathrm{~h}$ in an oven before compounding. Selected compositions were mixed and extruded in Barbender corotating twin-screw extruder (make: CMEI, model: 16CME, SPL, and chamber size $70 \mathrm{~cm}^{3}$ ). The mixing speed of $100 \mathrm{rpm}$ was maintained for all the compositions. The extrudates from the die were quenched in cold water and then pelletized. In the melt blending, the temperature profile of the extrusion were zone $1\left(200^{\circ} \mathrm{C}\right)$, zone $2\left(210^{\circ} \mathrm{C}\right)$, zone $3\left(220^{\circ} \mathrm{C}\right)$, zone $4\left(240^{\circ} \mathrm{C}\right)$, and zone $5\left(260^{\circ} \mathrm{C}\right)$, respectively. The extrudates of the compositions were pelletized using pelletizing machine. The pellets of the extrudates were predried at $100^{\circ} \mathrm{C}$ in vacuum oven for $24 \mathrm{~h}$ and injection moulded in a reciprocating screw injection moulding machine (Windsor, $50 \mathrm{~T})$ to produce test specimens. The processing temperature at zone $1\left(220^{\circ} \mathrm{C}\right)$ and zone $2\left(250^{\circ} \mathrm{C}\right)$ in injection moulding machine barrel was maintained, respectively. The mould temperature was maintained at $35^{\circ} \mathrm{C}$. The details of the composites fabricated for present investigation are given in Table 2.

2.3. Dynamic Mechanical Analysis. DMA is a technique, which is used to study the stress, temperature, and frequency of the material when it is subjected to the small deformation by sinusoidal load. It is used to measure the stiffness and damping in terms of moduli and $\operatorname{Tan} \delta$. It was carried out using TA instruments DMA Q 800 Dynamic Mechanical Analyzer with specimen dimension of $20 \mathrm{~mm} \times 12 \mathrm{~mm} \times$ $1.6 \mathrm{~mm}$. The measurements were carried out in a three-point bending mode of the equipment and the corresponding viscoelastic properties were determined as a function of temperature. The temperature range was $-60^{\circ} \mathrm{C}$ to $150^{\circ} \mathrm{C}$ at a heating rate of $5^{\circ} \mathrm{C} \mathrm{min}^{-1}$ under nitrogen flow. The samples were scanned at a frequency of $1 \mathrm{~Hz}$. 


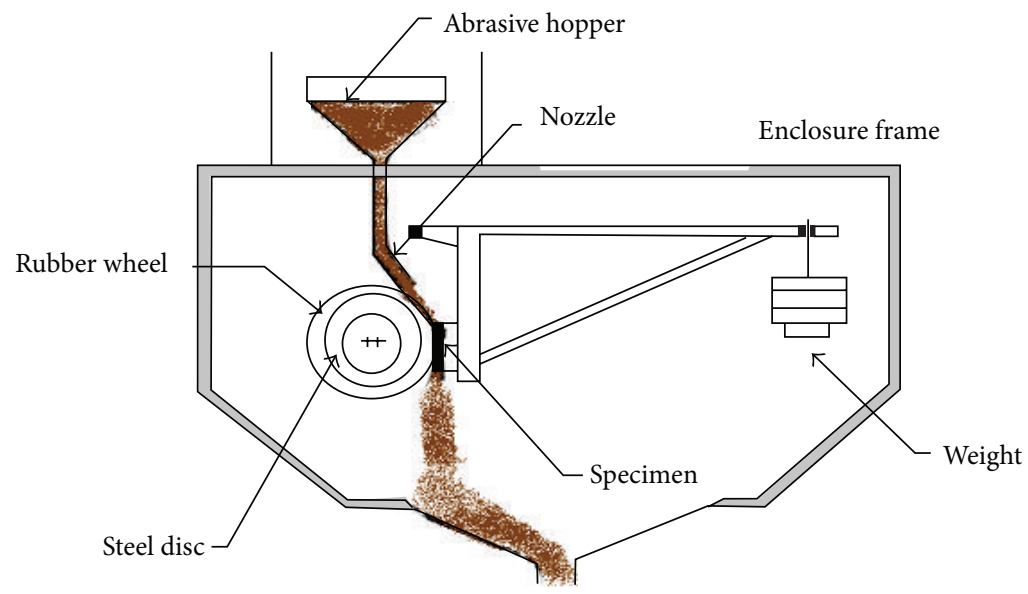

FIGURE 1: Schematic diagram of dry sand rubber wheel abrasion tester.

TABLE 3: Test parameters considered for three-body abrasive wear test.

\begin{tabular}{lc}
\hline Parameters & Test conditions \\
\hline $\begin{array}{l}\text { Load } \\
\text { Rotational speed of rubber } \\
\text { wheel }\end{array}$ & $40 \mathrm{~N}$ \\
Diameter of rubber wheel & $200 \mathrm{rpm}$ \\
Abrasive particles & $228.6 \mathrm{~mm}$ \\
Size of the specimen & $600 \mu \mathrm{m}$ \\
Total test duration & $76 \mathrm{~mm} \times 26 \mathrm{~mm} \times 6 \mathrm{~mm}$ \\
Abrading distance & $5.25,10.25 \mathrm{and} 15.25 \mathrm{~min}$ \\
Sand flow rate & $752 \mathrm{~m}, 1468 \mathrm{~m}, 2185 \mathrm{~m}$. \\
& $255 \pm 5 \mathrm{~g} / \mathrm{m}$. \\
\hline
\end{tabular}

2.4. Three-Body Abrasive Wear Tests. Three-body abrasive wear studies of TCE with and without SGF and their composites were studied on a dry sand/rubber wheel abrasion test rig as shown in Figure 1. The detailed test procedures were discussed elsewhere $[8,28]$. After conducting a set of routine experiments, the final test conditions were implemented and noted in Table 3 . The weight loss due to wear was noted down. Volume loss $(\Delta v)$ due to wear and the specific wear rate $\left(K_{s}\right)$ were calculated after the test using the following equations:

$$
\begin{gathered}
\Delta v=\frac{\Delta m}{\rho}\left(\mathrm{mm}^{3}\right) \\
K_{s}=\frac{\Delta v}{F_{N} D}\left(\mathrm{~m}^{3} / \mathrm{Nm}\right),
\end{gathered}
$$

where $\Delta v$ is the volume loss due to wear, $\Delta m$ is the mass loss of the specimen, $\rho$ is the experimental density of the sample, $F_{N}$ is the applied load, and $D$ is the abrading distance. Three replicates of wear tests were performed for each sample to minimize data scattering and the average of the three replicate test results is reported as the specific wear rate in this work.
TABLE 4: Control factors and levels used in the three-body abrasive wear tests.

\begin{tabular}{lccc}
\hline Control factors & \multicolumn{3}{c}{ Levels } \\
& 1 & 2 & 3 \\
\hline PTFE + particulate filler content (composition) & 15 & 32 & 40 \\
$(A)$, in $(\%)$ & 212 & 425 & 600 \\
Abrasive sand particle size $(B)$, in $(\mu \mathrm{m})$ & 752 & 1468 & 2185 \\
Abrading distance $(C)$, in $(\mathrm{m})$ & &
\end{tabular}

Also, correlation of wear data with mechanical properties was carried out and the correlation coefficient can be calculated by the following equation:

$$
r=\frac{n\left(\sum x y\right)-\left(\sum x\right)\left(\sum y\right)}{\sqrt{\left[n\left(\sum x^{2}\right)-\left(\sum x\right)^{2}\right]\left[n\left(\sum y^{2}\right)-\left(\sum y\right)^{2}\right]}},
$$

where $r$ is the correlation coefficient, $n$ is the number of observations, $x$ is the independent variable (in this case, reciprocal of mechanical properties), and $y$ is the dependent variable (in this case, it is wear volume of the composites).

2.5. Worn Surface Morphology. After wear test, the worn surface morphology of the composites was carried out using E-SEM, Quanta 200 model scanning electron microscope instrument with a voltage of $20 \mathrm{kV}$.

2.6. Design of Experiments. Designs of experiments were applied on three-body abrasive wear behaviour of polymer composites [34-39]. In this research article, three factors, that is, filler content/composition $(A)$, abrasive particle size $(B)$, and abrading distance $(C)$ each at three levels, are considered in this study in accordance with $L_{27}\left(3^{13}\right)$ orthogonal array. The control factors and their levels are listed in Table 4.

The experimental observations are further transformed into signal-to-noise $(S / N)$ ratios. There are three categories of quality characteristic in the $S / N$ ratio of the Taguchi method: the lower the better, the higher the better, and the nominal the better. These can be calculated as logarithmic transformation 
of the loss function. Wear volume loss $(\Delta v)$ as "lower is better" performance characteristic is selected and is determined by below given equation:

$$
S / N=-10 \log \frac{1}{n}\left(\Sigma y^{2}\right),
$$

where " $n$ " is the number of observations and " $y$ " is the observed data.

A statistical ANOVA was performed to identify the control factors that are statistically significant. With the $S / N$ ratio and ANOVA analysis, the optimal combination of three-body abrasive wear parameters is predicted to acceptable level of accuracy.

\section{Results and Discussion}

3.1. Dynamic Mechanical Analysis. The results of dynamic mechanical analysis were discussed in the following sections.

3.1.1. The Effect of Fiber and Filler Loading on Storage Modulus, Loss Modulus, and Tan $\delta$. A dynamic mechanical analysis (DMA) was used to evaluate dynamic elastic (both storage and loss) moduli and Tan $\delta$ of the fiber and particulatereinforced TCE + PTFE composite materials. The storage modulus, loss modulus, and Tan $\delta$ of TCE hybrid composites are plotted against temperature and demonstrated in Figure 2. These data provides insight into the stiffness of the composites, representing the elastic nature of the material [40]. Figure 2 shows the plots of storage modulus and loss modulus, against temperature in the range from -60 to $140^{\circ} \mathrm{C}$ for the various wt.\% $(15,32$ and 40$)$ of TCE composites. It is shown from Figure 2 that dynamic elastic modulus values (both storage and loss) in the glassy region have increased with the increasing fiber and filler loading. However, the composite containing combination of fibers and fillers with 40 wt. $\%\left(17.5 \% \mathrm{GF}+2.5 \% \mathrm{CF}+5 \% \mathrm{SiC}+5 \% \mathrm{Al}_{2} \mathrm{O}_{3}\right)$ shows remarkably higher storage and loss moduli.

In general, there are three physical states of polymer materials: glassy region, glass transition region, and rubbery region. In the glassy region, the movement of chain segments is mostly "frozen" due to tight packing, so the material is prone to store more energy; this results in a high storage modulus [41]. The storage moduli of hybrid TCE + PTFE composites are high at $-60^{\circ} \mathrm{C}$ and decreases as the temperature increases. This is because the components become more mobile and lose their close packing arrangement, leading to a very noticeable decrease of storage modulus in the glass transition region. As a result, in the rubbery region there is no significant change in storage modulus. This can be attributed to a highly entangled state of the polymer macromolecules [42]. The stiffening effect of SCFs and ceramic fillers like fine $\mathrm{SiC}$ and $\mathrm{Al}_{2} \mathrm{O}_{3}(<10 \mu \mathrm{m})$ particles on the TCE + PTFE composite is stronger than that of the SGFs for temperatures below $-60^{\circ} \mathrm{C}$, which can be ascribed to the shape of different fillers. Also, TCE reinforced with $40 \mathrm{wt} . \%$ fiber and fillers had higher values of storage modulus as compared to those with $32 \mathrm{wt} . \%$ fibers + fillers and $15 \mathrm{wt} . \%$ fillers. This is because of the reinforcement fibers and fillers, leading to a strong and

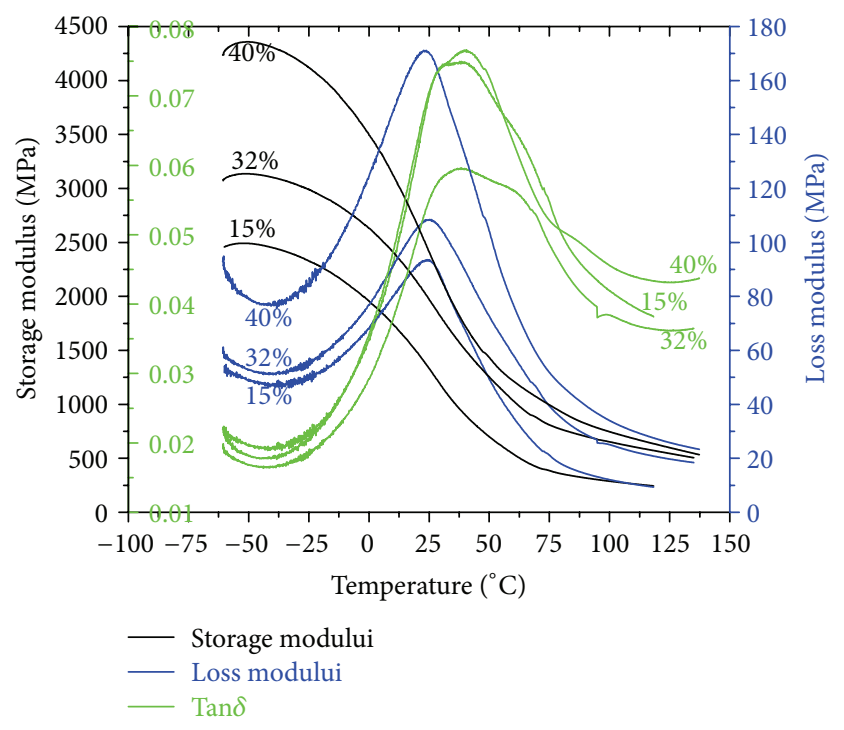

FIGURE 2: DMA thermogram depicting the storage modului, loss modului, and Tan $\delta$ of TCE + PTFE filled hybrid composites.

stiff interface between fiber/filler and polymer molecules [43]. In addition, TCE hybrid composites filled with micron sized filler particles possess higher storage modulus than those with large particles (fibers) and greater surface area occupied by the fillers, resulting in the effective matrixfiller interactions. The loss modulus peaks of TCE hybrid composites filled with $40 \mathrm{wt}$ \% fiber + filler content become broader than those with $32 \mathrm{wt} . \%$ fiber + filler and $15 \mathrm{wt} . \%$ filler content, because of hindrance of the molecular motion.

The ratio of loss modulus to storage modulus is referred to as internal damping or the Tan $\delta$. Generally, the major contributing causes of composite damping are (a) the nature of the matrix and filler; (b) the nature of the interphase; (c) frictional damping due to slippage in the unbound regions between the filler and the matrix interface, or delamination, and (d) energy dissipation in the area of matrix cracks. The damping peak usually occurs in the glass transition region and is associated with the movement of side groups or low molecular-weight units and molecular chains within the rubbers. Therefore, the higher the damping peak, the greater the degree of molecular mobility [44]. It can be seen from Figure 2, that the incorporation of $32 \mathrm{wt} . \%$ fiber + filler loading into the TCE composite decreased the damping characteristics of the composites, causing a lower and broader damping peak. This could be explained because the fiber/filler acted as a barrier to the mobility of polymer chains, which restricted the segmental motions of polymer through the strong interaction between fiber/filler and polymer molecular chains, indicating the reinforcing nature of filler with polymers [43]. Moreover, there was a reduction of the damping peak for $15 \mathrm{wt} . \%$ filler in TCE composites and hence a greater improvement in the fiber reinforcements. The effect of the fiber + filler wt.\% in TCE composites on DMA results is summarized in Table 5. 
TABLE 5: Dynamic mechanical properties of TCE + PTFE filled hybrid composites.

\begin{tabular}{lcccc}
\hline TCE + (fiber + filler wt.\%) & Storage modulus $(\mathrm{MPa})$ & Loss modulus $(\mathrm{MPa})$ & $\tan \delta$ & $\mathrm{Glass}$ transition $\left(T_{g}\right),{ }^{\circ} \mathrm{C}$ \\
\hline $85+(15)$ & 2505.41 & 93.72 & 0.0750 & 24.65 \\
$68+(12+20)$ & 3151.16 & 109.17 & 0.0600 & 24.65 \\
$60+(20+20)$ & 4381.81 & 171.26 & 0.0768 & 23.56 \\
\hline
\end{tabular}

3.2. The Effect of Fiber and Filler Loading on Wear Volume and Specific Wear Rate. The wear volume of TCE + PTFE and its composites filled with SGFs and particulates (carbon, $\mathrm{SiC}$, and $\mathrm{Al}_{2} \mathrm{O}_{3}$ ) abraded with three different silica sand abrasive particle size of 212,425 , and $600 \mu \mathrm{m}$, to a distance of 752,1468 , and $2185 \mathrm{~m}$ and for a fixed load of $40 \mathrm{~N}$ is listed in Table 6. It can be seen that the wear volume increases with increase in abrading distance, size of abrasives, and increasing in fiber and particulates loading. It is also evident from Table 6 that PTFE particles as reinforcement into TCE enhanced the abrasion resistance. However, the incorporation of SGFs increased the wear volume of TCE + PTFE composite. Furthermore, the reinforced effect of hard particles, namely, $\mathrm{SiC}$ and $\mathrm{Al}_{2} \mathrm{O}_{3}$ are less effective in SGFs reinforced TCE + PTFE composite. In the case of TCE + PTFE composite with $20 \mathrm{wt} . \%$ SGFs, the wear volume was approximately increased by $173 \%$ than that for TCE + PTFE composite. It should be noted that the increase in wear volume was greater when SGFs, carbon, $\mathrm{SiC}$, and $\mathrm{Al}_{2} \mathrm{O}_{3}$ were used in combination. The wear volume for TCE + PTFE was $130.8759 \mathrm{~mm}^{3}$ under a load of $40 \mathrm{~N}$, while that of hybrid TCE composite was $396.8096 \mathrm{~mm}^{3}$. The TCE + PTFE composite show an increase in wear resistance by 170 and $225 \%$ with comparison to that of TCE + PTFE + SGF reinforced and hybrid TCE composites, respectively. Meanwhile, adding micron sized ceramic particles (10 wt.\%) into SGFs reinforced TCE + PTFE drastically increased the wear volume by $303 \%$. Obviously, there is an adverse effect of ceramic fillers on the enhancement of abrasion resistance of TCE filled PTFE. This could be due to the abrasive nature of glass fibers and hard particles into the soft segment, that is, TCE filled PTFE composite. Better adhesion was found between TCE and PTFE, as it exhibited higher wear resistance to abrasive wear. Addition of SGF, carbon fiber, $\mathrm{SiC}$, and $\mathrm{Al}_{2} \mathrm{O}_{3}$ increased the concentration of fiber and filler contents in the TCE + PTFE composites, which is detrimental to abrasive wear behaviour. In addition, it can be seen that the wear volume of TCE + PTFE and its composites increased with increase in particle size of the silica sand used as abrasives.

The specific wear rate decreases with increasing abrading distance and increases with the particle size of the abrasive. As seen in Figures 3(a)-3(c), when the silica sand particles are of coarse grade $(600 \mu \mathrm{m})$, the specific wear rate starts to decrease drastically with increase in abrading distance. Higher specific wear rate was noticed for TCE hybrid composite compared to TCE + PTFE composite.

TCE + PTFE + SGF and TCE hybrid composites showed excessive wear after $1468 \mathrm{~m}$ abrading distance, respectively, in the experiments and the wear debris corresponded was in the form of large slices (Figure 4) under a load of $40 \mathrm{~N}$ with $212 \mu \mathrm{m}$ silica sand abrasives. It was found that glass fiber reinforcement could effectively reduce the wear volume of TCE + PTFE composite with comparison to that of ceramic filler filled TCE hybrid composite. By comparison, SGF + TCE + PTFE had slightly better wear resistance than TCE hybrid composite.

For abrasion of polymeric composites, many attempts have been made to understand the tribo behaviour of various materials at several operating parameters, and the efforts continue. Three-body abrasion of polyester composites reinforced with randomly distributed short glass fibres has been studied by Chand et al. $[39,45]$, and it was found that increasing the size of the abrasive particles and the applied load worsened the wear property of the composite. Meanwhile, increasing the sliding velocities reduced the wear rate, and increasing the volume fraction of the glass fibres, according to the high energy theory, improved the wear properties, whereby a higher energy was required to facilitate the failure in the fibrous regions. The wear mechanism was predominated by matrix failure, pitting, cracks, and grooves. Harsha et al. $[46,47]$ studied the effect of fibres, solid lubricants, and applied load on the three-body abrasive wear characteristics of polyaryletherketone (PAEK) composites and showed that the ketone/ether ratio highly influenced the wear resistance of the composites especially at a higher load (12 N). Surprisingly, the addition of fillers and/or fibres to the PAEK worsened its three-body abrasive wear characteristics. Moreover, carbon fibres provided an inferior support for the PAEK composites as compared to glass fibres. Filler addition to the two phase composite showed worsening of the abrasion resistance. The results of the present work are also consistent with the literature findings $[46,47]$.

3.3. Correlation of Wear Data with Mechanical Properties. The hardness and tensile properties of TCE composites are shown in Table 2. The primary reasons for adding fillers or reinforcing fibers to polymers is to improve their mechanical properties, but the effects on wear rate are not invariably beneficial. According to Lancaster [48], the product of " $S$ " and " $e$ " (where " $S$ " is the ultimate tensile strength and " $e$ " the ultimate elongation) is a very important factor which controls the abrasive wear behaviour of composites. Reinforcement with the fibers/fillers increases the tensile strength (" $S$ ") of neat polymer, they usually decrease ultimate elongation to break (" $e$ ") and hence product "S $e$ " may become smaller than that of neat polymer. Hence, reinforcement usually leads to deterioration in the abrasive wear resistance. Various theories have been proposed to interpret the abrasive wear performance of the composites. According to Ratner et al. [49] the wear rate of material is inversely proportional to the product of " $\mathrm{S} e$ ". In the present investigation, the relationship between wear volume versus $(e)^{-1},(\mathrm{He})^{-1}$ (where $H$ is the hardness of 


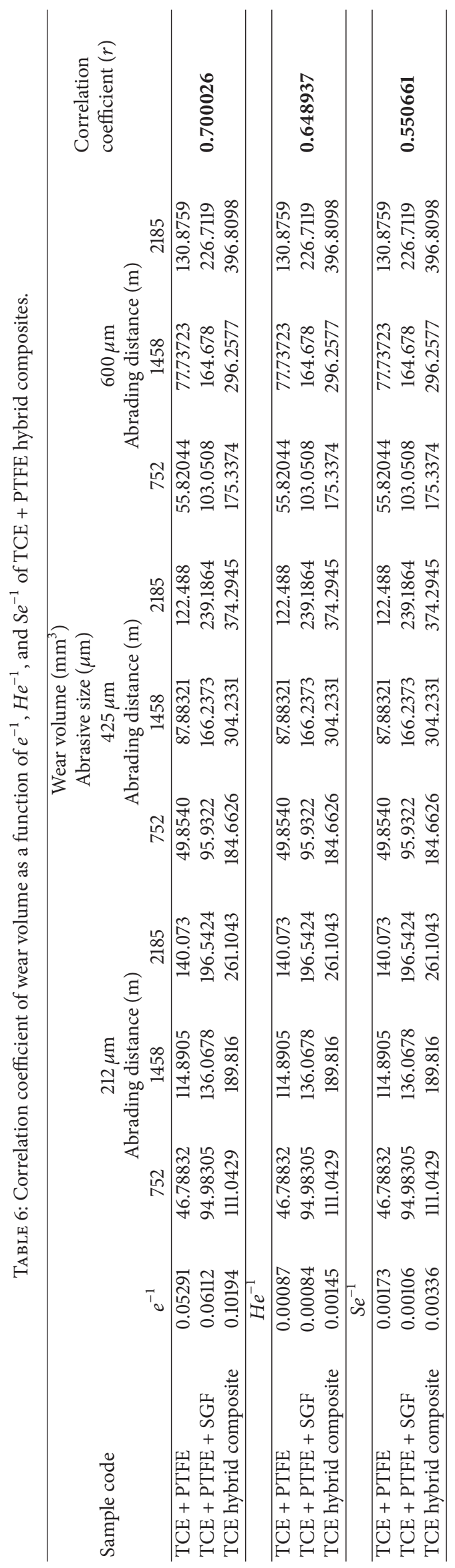




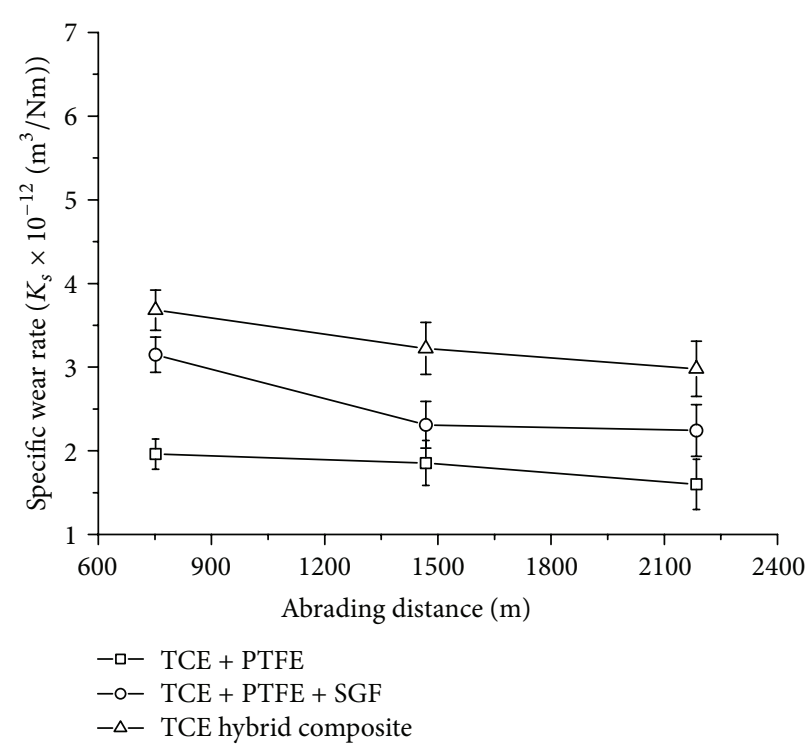

(a)

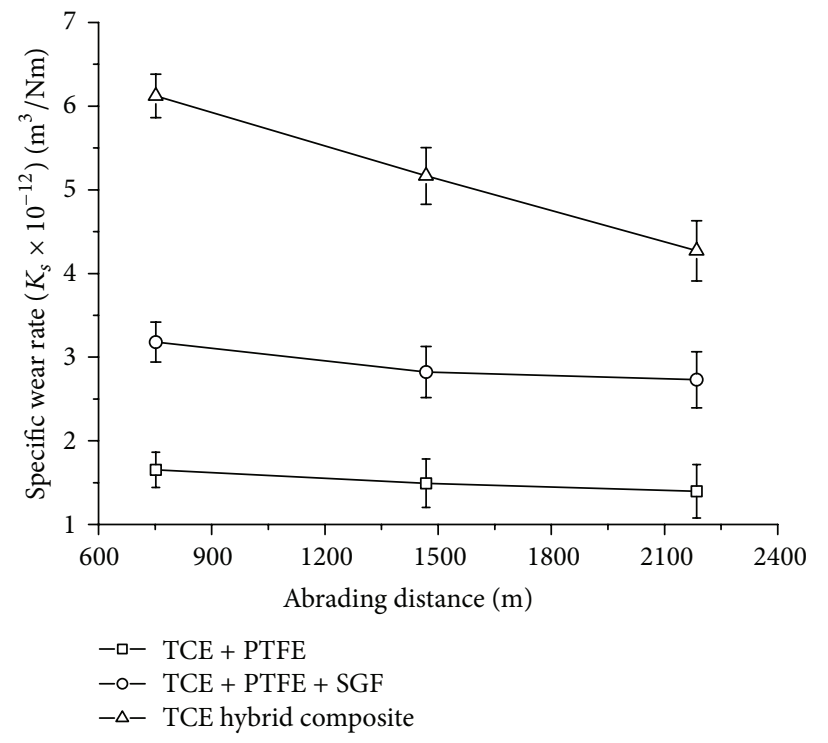

(b)

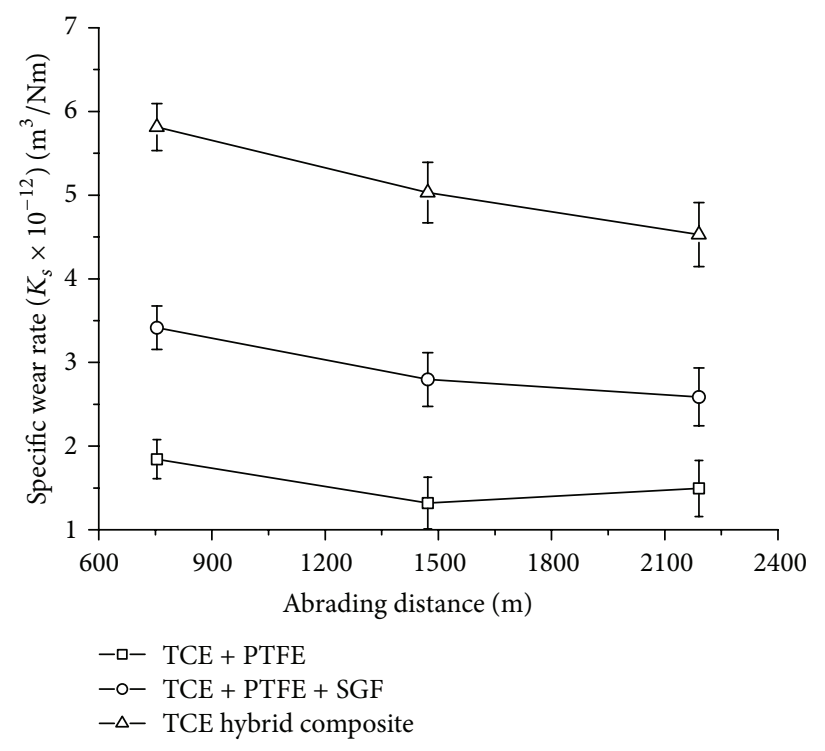

(c)

Figure 3: (a) Effect of abrading distance on $K_{s}$ of TCE + PTFE filled hybrid composites at $40 \mathrm{~N}$ (212 $\mu \mathrm{m}$ silica sand). (b) Effect of abrading distance on $K_{s}$ of TCE + PTFE filled hybrid composites at $40 \mathrm{~N}$ (425 $\mu \mathrm{m}$ silica sand). (c) Effect of abrading distance on $K_{s}$ of TCE + PTFE filled hybrid composites at $40 \mathrm{~N}(600 \mu \mathrm{m}$ silica sand $)$.

the composite material), and $(\mathrm{Se})^{-1}$ with different abrading distance and varying abrasive particle sizes was studied. Composite with $40 \mathrm{wt} \%$ fiber + filler in TCE matrix exhibits lower "S" and " $e$ " values but moderate " $H$ " value showed higher specific wear rate and wear volume with least resistance to three-body abrasion wear. Composite with $32 \mathrm{wt} . \%$ fiber + filler in TCE matrix possesses higher " $S$ " and " $H$ " values with moderate " $e$ " value, exhibited moderate specific wear rate, wear volume, and resistance to three-body abrasion wear. Composite TCE + PTFE with lower " $S$ " and " $H$ " values but higher " $e$ " value showed lower specific wear rate, wear volume, and excellent resistance to three-body abrasion wear in the study group. The decrease in elongation in TCE + PTFE reinforced with SGF composite and TCE + PTFE hybrid composites is due to the fiber reinforcement and inclusions of filler particulates which results in deterioration of abrasive wear performance. Hence, the fiber/fillers were detrimental to the abrasive wear resistance of ductile polymers, which reduces toughness. Table 6 , shows the correlation coefficient values of wear volume as a function of $e^{-1}, \mathrm{He}^{-1}$, and $\mathrm{Se}^{-1}$ of TCE composites with different abrading distance and abrasive particles size. The term reciprocal of elongation $(e)^{-1}$ ranked first in correlation with correlation coefficient value of 0.700026 , followed by $(\mathrm{He})^{-1}$ and $(\mathrm{Se})^{-1}$ with correlation coefficient values of 0.648937 and 0.550661 , respectively, for the composites studied. With this, it can be concluded 


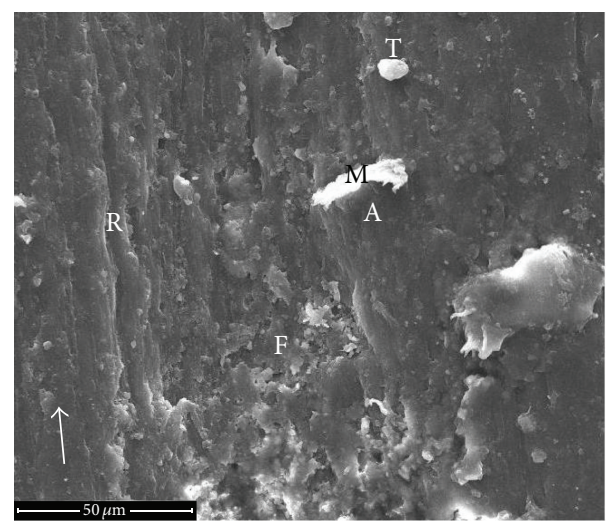

FIGURE 4: Scanning electron micrograph of TCE + PTFE composite abraded with sand particle size of $212 \mu \mathrm{m}$, to a distance of $2185 \mathrm{~m}$ and at load of $40 \mathrm{~N}$.

that ultimate elongation to break (e) influences the threebody abrasive wear behaviour of the composite compared to ultimate tensile strength $(S)$ and hardness of the composite $(H)$ in the present investigation.

3.4. Worn Surface Morphology. Abrasive wear occurs generally by three different mechanisms, that is, microploughing, microcutting, and microcracking [45]. Worn surfaces of materials were examined to find out predominant wear mechanisms. SEM photomicrograph of damaged surface for TCE + PTFE composite is shown in Figure 4. The deep grooves in the abrading direction (indicated with an arrow) are formed due to the microcutting action by sharp abrasive particles which are seen on the surface. Displacement of material had occurred by action of rolling and sliding of abrasive particle leading to the formation of furrows (F) and forming ridges (R) in transverse direction, similar to ploughing process. Material is deformed under load through ploughing and cutting with subsequent application of load. The deformed material (M) can be seen which is adhering to abraded surface (A) resulting in the ductile nature of the matrix material. PTFE particulates $(\mathrm{T})$ can be seen on the surface. The worn surface provides evidence of rolling action of abrasive particles which is dominant in the abrasion process compared to sliding action. The deep furrows and wear damage are due to the rolling action of abrasive particles. Formation of ridges and shallow grooves are least, and this may be due to the sliding action of abrasive particles. Figure 5 shows SEM micrograph of TCE + PTFE reinforced with SGF composite. It was noticed that SGF are completely embedded (E) in the TCE matrix. This is due to TCE, as a low melting polymer, and composites are processed by injection moulding. Hence, skin of TCE matrix is formed on the SGF fibers. The material damage can be observed which is due to the formation and propagation of cracks (C) at the surfaces. The wear debris (D) attached to surface in the form of thin layers indicates the grooves formation, which is due to the ductile nature of the matrix. Fibers pull out or fiber damage is absent and indicates good adhesion between fiber and matrix material. The cracks are visible in the abrading

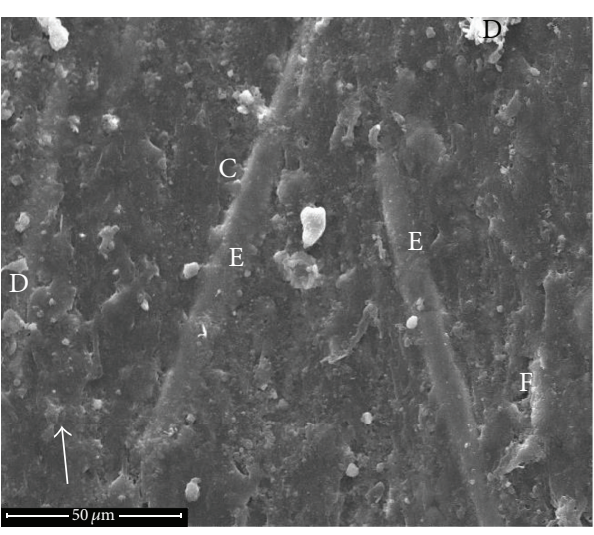

FIGURE 5: Scanning electron micrograph of TCE + PTFE with SGFs composite abraded with sand particle size of $212 \mu \mathrm{m}$, to a distance of $2185 \mathrm{~m}$ and at a load of $40 \mathrm{~N}$.

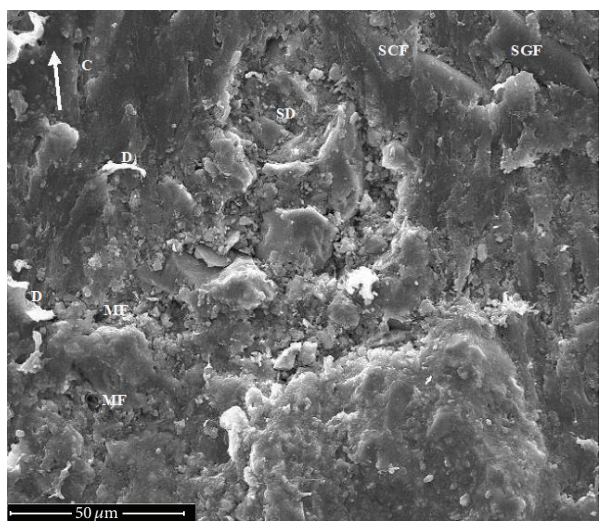

FIGURE 6: Scanning electron micrograph of TCE + PTFE + SGF filled with SCF, $\mathrm{SiC}$ and $\mathrm{Al}_{2} \mathrm{O}_{3}$ hybrid composite abraded with sand particle size of $212 \mu \mathrm{m}$, to a distance of $2185 \mathrm{~m}$ and at a load of $40 \mathrm{~N}$.

direction (indicated with an arrow) which is due to the microcutting by the abrasive particles. The worn surface also indicates the ploughing action by the abrasive particles in the wear direction. Figure 6 shows the damaged surface of TCE + PTFE, SGF, SCF, $\mathrm{Al}_{2} \mathrm{O}_{3}$, and SiC filled hybrid composite. Severe damage $(\mathrm{SD})$ can be seen in the micrograph which resulted in higher wear volume loss. Fiber damage and removal can also be seen which has resulted in the higher specific wear rate of the composite in the study group. Cracks, furrows, and ridges can be seen which result due to ploughing and cutting action of abrasive particles. Microfillers (MF) are loosely debonded to the matrix material which resulted in the formation of pits. The sharp edges of microfillers turned out to be abrasive particles and hence increase the wear volume. Wear debris in the form of thin film adhering to the surfaces indicates the toughness of the matrix material.

3.5. Statistical Analysis of Wear. The analysis was made using the software MINITAB 16, specifically used for the DOE applications. Table 7 presents the plan of experiments with output results using $L_{27}$ orthogonal array. Abrasive wear 
TABLE 7: Experimental design using $L_{27}$ orthogonal array.

\begin{tabular}{|c|c|c|c|c|c|c|c|}
\hline Exp. Number & $\begin{array}{l}\text { Filler content (wt.\%) } \\
(\text { PTFE + particulate) }\end{array}$ & $\begin{array}{l}\text { Sand size } \\
\qquad(\mu \mathrm{m})\end{array}$ & Distance $(\mathrm{m})$ & $\begin{array}{l}\text { Weight loss } \\
\text { (g) }\end{array}$ & $\begin{array}{l}\text { Wear volume } \\
\quad\left(\mathrm{mm}^{3}\right)\end{array}$ & $\begin{array}{l}\text { Specific wear } \\
\text { rate } \times 10^{-12} \\
\left(\mathrm{~m}^{3} \mathrm{~N}^{-1} \mathrm{~m}^{-1}\right)\end{array}$ & $\begin{array}{l}S / N \text { ratios } \\
\quad(\mathrm{dB})\end{array}$ \\
\hline 1 & 15 & 212 & 752 & 0.0641 & 46.78832 & 1.555463 & -33.4027 \\
\hline 2 & 15 & 212 & 1468 & 0.1574 & 114.8905 & 1.956582 & -41.2057 \\
\hline 3 & 15 & 212 & 2185 & 0.1919 & 140.073 & 1.602666 & -42.9271 \\
\hline 4 & 15 & 425 & 752 & 0.0683 & 49.85401 & 1.657381 & -33.9540 \\
\hline 5 & 15 & 425 & 1468 & 0.1204 & 87.88321 & 1.496649 & -38.8781 \\
\hline 6 & 15 & 425 & 2185 & 0.1678 & 122.4818 & 1.401393 & -41.7614 \\
\hline 7 & 15 & 600 & 752 & 0.0762 & 55.62044 & 1.849084 & -34.9047 \\
\hline 8 & 15 & 600 & 1468 & 0.1065 & 77.73723 & 1.323863 & -37.8126 \\
\hline 9 & 15 & 600 & 2185 & 0.1793 & 130.8759 & 1.497436 & -42.3372 \\
\hline 10 & 32 & 212 & 752 & 0.1401 & 94.98305 & 3.157681 & -39.5529 \\
\hline 11 & 32 & 212 & 1468 & 0.2007 & 136.0678 & 2.317231 & -42.6751 \\
\hline 12 & 32 & 212 & 2185 & 0.2899 & 196.5424 & 2.248769 & -45.8691 \\
\hline 13 & 32 & 425 & 752 & 0.1415 & 95.9322 & 3.189235 & -39.6393 \\
\hline 14 & 32 & 425 & 1468 & 0.2452 & 166.2373 & 2.831016 & -44.4146 \\
\hline 15 & 32 & 425 & 2185 & 0.3528 & 239.1864 & 2.736687 & -47.5747 \\
\hline 16 & 32 & 600 & 752 & 0.152 & 103.0508 & 3.425893 & -40.2610 \\
\hline 17 & 32 & 600 & 1468 & 0.2429 & 164.678 & 2.804461 & -44.3327 \\
\hline 18 & 32 & 600 & 2185 & 0.3344 & 226.7119 & 2.593957 & -47.1095 \\
\hline 19 & 40 & 212 & 752 & 0.181 & 111.0429 & 3.691587 & -40.9098 \\
\hline 20 & 40 & 212 & 1468 & 0.3094 & 189.816 & 3.23256 & -45.5667 \\
\hline 21 & 40 & 212 & 2185 & 0.4256 & 261.1043 & 2.987463 & -48.3363 \\
\hline 22 & 40 & 425 & 752 & 0.301 & 184.6626 & 6.139048 & -45.3276 \\
\hline 23 & 40 & 425 & 1468 & 0.4959 & 304.2331 & 5.181082 & -49.6641 \\
\hline 24 & 40 & 425 & 2185 & 0.6101 & 374.2945 & 4.282546 & -51.4643 \\
\hline 25 & 40 & 600 & 752 & 0.2858 & 175.3374 & 5.829037 & -44.8775 \\
\hline 26 & 40 & 600 & 1468 & 0.4829 & 296.2577 & 5.04526 & -49.4334 \\
\hline 27 & 40 & 600 & 2185 & 0.6468 & 396.8098 & 4.540158 & -51.9716 \\
\hline
\end{tabular}

responses and calculated signal to noise $(S / N)$ ratio are shown in Table 7 . The overall mean for the $S / N$ ratio of the wear volume was found to be $-43.1912 \mathrm{~dB}$. Figures 7 and 8 graphically denote the effect of the control factors on the wear volume. Process parameter settings with the highest $S / N$ ratio always gave the optimum quality with minimum variance. The graphs show the change of the $S / N$ ratio when the setting of the control factor was changed from one level to the other. The best wear volume was at the higher $S / N$ ratio values in the response graphs. From the graph, it is clear that control factor combination of $A_{1}, B_{1}$, and $C_{1}$ gives minimum wear volume. Thus minimum wear volume for the developed composite materials is obtained when the filler content $(A)$, abrasive particle size $(B)$, and abrading distance $(C)$ are at the lowest level. This may be due to the factor that the PTFE content in the composite as fillers tends the abrasive particles to slip during abrasion process, resulting in low specific wear rate of the composite.

The $S / N$ ratio response is presented in Table 8 . The $S / N$ ratio delta values of $A, B$, and $C$ are 8.93, 1.40, and 7.39, respectively. The strongest influence on the wear volume loss
TABLE 8: Response data for $S / N$ ratios under three-body abrasion.

\begin{tabular}{lccc}
\hline Level & Composition $(A)$ & Sand size $(B)$ & Distance $(C)$ \\
\hline 1 & -38.58 & -42.27 & -39.20 \\
2 & -43.49 & -43.63 & -43.78 \\
3 & -47.51 & -43.67 & -46.59 \\
Delta & 8.93 & 1.40 & 7.39 \\
Rank & 1 & 3 & 2 \\
\hline
\end{tabular}

was exerted by factor $A$, followed by factors $C$, and $B$, respectively. The interaction effects of control factors plot for $S / N$ ratio is shown in Figure 8. Interactions do not occur when the lines on the interaction plots are parallel and strong interactions occur between control factors when the lines cross. Observation of Figure 8 yields an interaction between filler content versus sand particle size and abrading distance versus sand particle size. In order to justify the interactions, statistical analysis (ANOVA) was carried out. 


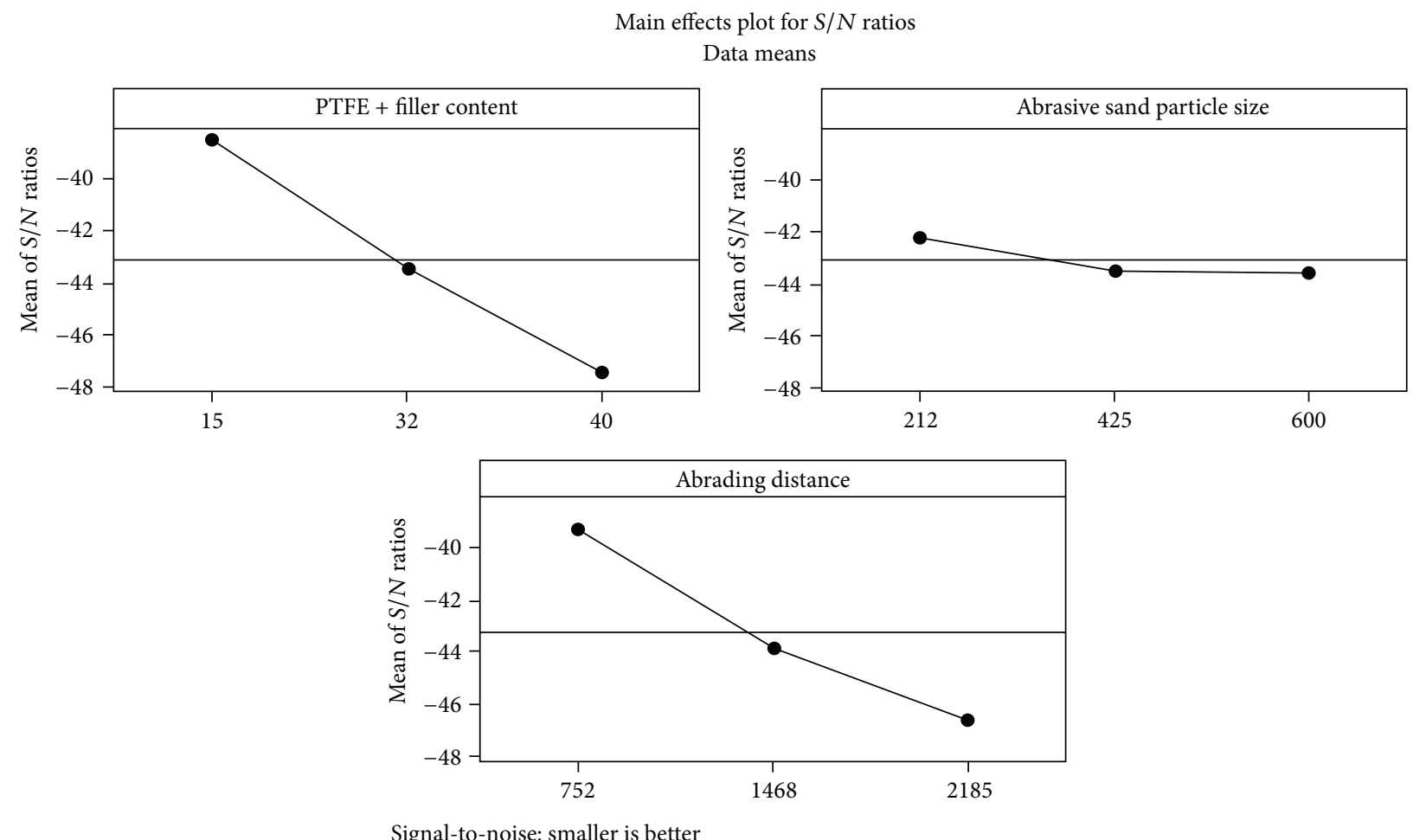

Signal-to-noise: smaller is better

FIGURE 7: Main effects plot for $S / N$ ratio of TCE composites.

TABLE 9: ANOVA data of TCE + PTFE filled hybrid composites under three-body abrasion.

\begin{tabular}{|c|c|c|c|c|c|c|c|}
\hline Source & $\mathrm{DF}$ & Seq SS & Adj SS & Adj MS & $F$ & $P$ value & $P(\%)$ \\
\hline Composition $(A)$ & 2 & 120998 & 120998 & 60499 & 262.20 & 0.000 & 52.46 \\
\hline Abrasive sand size $(B)$ & 2 & 8294 & 8294 & 4147 & 17.97 & 0.001 & 3.59 \\
\hline Abrading distance $(C)$ & 2 & 76247 & 76247 & 38123 & 165.23 & 0.000 & 33.05 \\
\hline Composition $\times$ sand size $(A \times B)$ & 4 & 13681 & 13681 & 3420 & 14.82 & 0.001 & 5.93 \\
\hline Sand size $\times$ distance $(B \times C)$ & 4 & 642 & 642 & 161 & 0.70 & 0.616 & 0.27 \\
\hline Composition $\times$ distance $(A \times C)$ & 4 & 8934 & 8934 & 2234 & 9.68 & 0.004 & 3.90 \\
\hline Error & 8 & 1846 & 1846 & 231 & & & 0.80 \\
\hline Total & 26 & 230642 & & & & & 100 \\
\hline
\end{tabular}

$S=15.1899, R-\mathrm{Sq}=99.20 \%$, and $R-\mathrm{Sq}=97.40 \%$.

DF: degree of freedom, Seq SS: sequential sum of squares, Adj SS: adjusted sum of squares, Adj MS: adjusted mean squares, $F$ : variance, $P$ value: test statistics, and $P(\%)$ : percentage of contribution.

3.5.1. ANOVA and the Effects of Control Factors. ANOVA is a statistical design method used to break up the individual effects from all control factors. The percentage contribution of each factor is employed to measure the corresponding effect on the quality characteristics. The ANOVA with wear volume results are listed in Table 9. This analysis was undertaken for a level of significance of $5 \%$, that is, for level of confidence $95 \%$. The last column of the table indicates the order of significance among control factors and interactions. It could be observed from Table 9 that the control factor $A(P=0.0000)$ has greater static influence of $52.46 \%, C(P=0.0000)$ has an influence of $33.05 \%$, and $B(P=0.001)$ has an influence of $3.59 \%$ on wear volume of the material system under study. However, the interaction between $A$ versus $B(P=0.001)$, $B$ versus $C(P=0.616)$, and $A$ versus $C(P=0.004)$ has an influence of $5.93 \%, 0.27 \%$, and $3.90 \%$, respectively, which show less significance of contribution on wear volume.

The present analysis shows that three-body abrasive test parameters and their interactions have both statistical and physical significance (percentage contribution is greater than error) in the wear behaviour of TCE composites. But interaction between $B$ versus $C$ has statistical significance but do not have physical significance [50], since error associated is more than percentage contribution of these interactions, which is evident from the ANOVA results.

3.5.2. Confirmation Experiment. The confirmation experiment is the final step in the DOE process. The purpose of the confirmation experiment is to validate the conclusions drawn during the analysis phase $[51,52]$. The estimated $S / N$ ratio 
Interaction plot for $S / N$ ratios

Data means

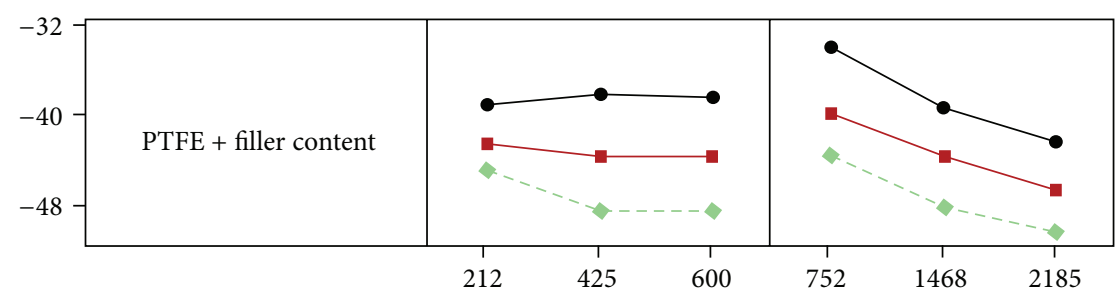

PTFE + filler content

$\rightarrow 15$

$\rightarrow-32$

$->40$

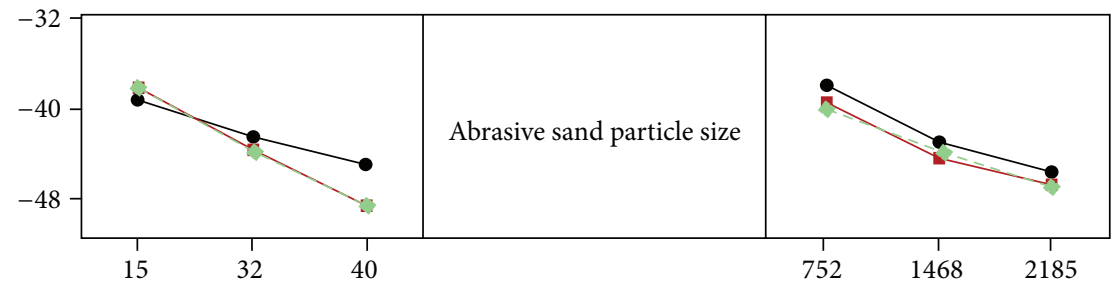

Abrasive sand particle size

- 212

$-425$

$-600$

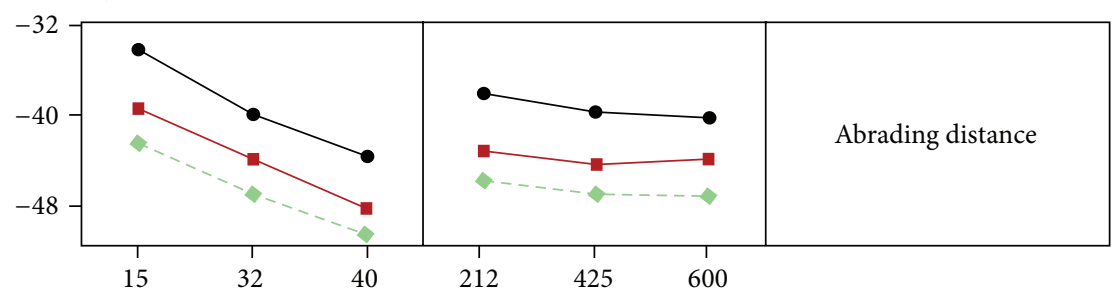

Abrading distance

- 752

- 1468

$->2185$

Signal-to-noise: smaller is better

FIGURE 8: Interaction plot for $S / N$ ratio of factors of TCE composites.

for specific wear rate using the optimum level of parameters can be calculated with the help of the following predictive equation $[52,53]$ :

$$
\bar{\eta}_{\mathrm{opt}}=\bar{T}+\sum_{j=1}^{k}\left(\eta_{j}-\bar{T}\right) ; \quad j=1,2, \ldots, k,
$$

where $\bar{T}=$ overall experimental average of $S / N$ ratio, $\eta_{j}=$ mean of the $S / N$ ratio at the optimum parameter level, and $k=$ number of main design parameters that significantly affect the wear rate of TCE composites.

The results of experimental confirmation using optimal wear parameters and comparison of the predicted specific wear rate with the actual specific wear rate using the optimal specific wear parameters are shown in Table 10. The improvement in $S / N$ ratio from the starting level to optimum level is $0.5513 \mathrm{~dB}$. The wear volume is reduced by $6.15 \%$. Therefore the wear volume performance is improved by using Taguchi method.

\section{Conclusions}

The three-body abrasive wear behavior of the TCE composites was studied as a function of particulate filler content, sand size, and abrading distance. The results were obtained as per Taguchi's $L_{27}$ orthogonal array and the following conclusion can be drawn from the present study. 
TABLE 10: Confirmation test for wear volume.

\begin{tabular}{lcccc}
\hline & Initial process & \multicolumn{2}{c}{ Optimal process parameter } & \\
Level & parameter & Prediction & Experimental & Improvement in the result \\
& $A_{1} B_{2} C_{1}$ & $A_{1} B_{1} C_{1}$ & $A_{1} B_{1} C_{1}$ & \\
\hline$S / N$ ratio $(\mathrm{dB})$ & -33.954 & -34.3611 & -33.4027 & $0.5513 \mathrm{~dB}$ \\
Wear volume $\mathrm{mm}^{3}$ & 49.85401 & 66.6763 & 46.78832 & $6.15 \%$ \\
\hline
\end{tabular}

(1) The storage and loss moduli of TCE + PTFE composite increased with the addition of fiber reinforcement and inclusion of ceramic fillers to short fiber reinforced TCE + PTFE (hybrid) composite. However, TCE + PTFE hybrid composite showed lower glass transition temperature.

(2) The TCE + PTFE composite showed better abrasion resistance as well as lower specific wear rate as compared to TCE + PTFE reinforced with SGF and ceramic fillers filled hybrid composites.

(3) Specific wear rate is more in TCE hybrid composite than that of TCE + PTFE composite. The carbon fiber, ceramic fillers, namely, $\mathrm{SiC}$ and $\mathrm{Al}_{2} \mathrm{O}_{3}$ were found to be detrimental to the abrasive wear performance. Glass fiber reinforcement to TCE + PTFE provides better abrasion resistance as compared to hybrid composites.

(4) The results indicated that the factor $\left(A_{1}\right)$ that is composition exerted the greatest effect on the wear, followed by the abrading distance $\left(C_{1}\right)$ and abrasive particle size $\left(B_{1}\right)$. The effect of combined factors on composition and sand size $(A \times B)$ on wear performance played a vital role.

(5) Design of experimental approach by Taguchi method enables to analyze the wear behavior successfully which has been influenced by number of parameter like filler content, sand size, and abrading distance.

(6) Correlation between the wear volume and selected mechanical properties emerged from the present investigation.

(7) SEM studies of the worn surfaces support the involved mechanisms during the abrasion process.

\section{Conflict of Interests}

The authors declare that there is no conflict of interests with any financial organization regarding the material discussed in this paper.

\section{References}

[1] G. W. Stachowiak, "Tribology of polymeric solids and their composites," in Wear: Materials, Mechanisms and Practice, chapter 10, pp. 223-267, John Wiley \& Sons, New York, NY, USA, 2005.

[2] M. W. Pascoe, "Plain and filled plastics materials in bearings: a review," Tribology, vol. 6, no. 5, pp. 184-190, 1973.
[3] M. J. Neale and M. Gee, Guide to Wear Problems and Testing for Industry, William Andrew, New York, NY, USA, 2001.

[4] Standard Terminology Relating to Wear and Erosion, vol. 3 of Annual Book of Standards, ASTM, 1987.

[5] Z. Jin, K. P. Pramoda, G. Xu, and S. H. Goh, "Dynamic mechanical behavior of melt-processed multi-walled carbon nanotube/poly(methyl methacrylate) composites," Chemical Physics Letters, vol. 337, no. 1-3, pp. 43-47, 2001.

[6] A. Hassan, N. M. Salleh, R. Yahya, and M. R. K. Sheikh, "Fiber length, thermal, mechanical, and dynamic mechanical properties of injection-molded glass-fiber/polyamide 6,6: plasticization effect," Journal of Reinforced Plastics and Composites, vol. 30, no. 6, pp. 488-498, 2011.

[7] S.-I. Huang, T.-H. Chn, and H. Chen, "Study on the composites of two sized silica filled in PTFE," Journal of Reinforced Plastics and Composites, vol. 25, no. 10, pp. 1053-1058, 2006.

[8] B. Suresha, B. L. Ravishankar, and L. Sukanya, "Dynamic mechanical analysis and three-body abrasive wear behavior of epoxy nanocomposites," Journal of Reinforced Plastics and Composites, vol. 32, no. 1, pp. 61-71, 2013.

[9] S. Thongsang, W. Vorakhan, E. Wimolmala, and N. Sombatsompop, "Dynamic mechanical analysis and tribological properties of NR vulcanizates with fly ash/precipitated silica hybrid filler," Tribology International, vol. 53, pp. 134-141, 2012.

[10] W. Brostow, W. Clwnkaew, and K. P. Menard, "Connection between dynamic mechanical properties and sliding wear resistance of polymers," Materials Research Innovations, vol. 10, no. 4, pp. 389-393, 2006.

[11] K. G. Budinski, "Resistance to particle abrasion of selected plastics," Wear, vol. 203-204, pp. 302-309, 1997.

[12] B. J. Briscoe, L. H. Yao, and T. A. Stölarski, "The friction and wear of poly (tetrafluoroethylene)-poly (ether-ether-ketone) composites: an initial appraisal of the optimum composition," Wear, vol. 108, no. 4, pp. 357-374, 1986.

[13] B. M. Sole and A. Ball, "On the abrasive wear behaviour of mineral filled polypropylene," Tribology International, vol. 29, no. 6, pp. 457-465, 1996.

[14] C. Liu, L. Ren, R. D. Arnell, and J. Tong, "Abrasive wear behavior of particle reinforced ultrahigh molecular weight polyethylene composites," Wear, vol. 225-229, part 1, pp. 199-204, 1999.

[15] A. A. Cenna, S. Allen, N. W. Page, and P. Dastoor, "Modelling the three-body abrasive wear of UHMWPE particle reinforced composites," Wear, vol. 254, no. 5-6, pp. 581-588, 2003.

[16] S. Bahadur and D. Gong, "Formulation of the model for optimal proportion of filler in polymer for abrasive wear resistance," Wear, vol. 157, no. 2, pp. 229-243, 1992.

[17] J. K. Lancaster, “Abrasive wear of polymers," Wear, vol. 14, no. 4, pp. 223-239, 1969.

[18] H. Czichos, "Influence of adhesive and abrasive mechanisms on the tribological behaviour of thermoplastic polymers," Wear, vol. 88, no. 1, pp. 27-43, 1983. 
[19] U. S. Tewari and J. Bijwe, "On the abrasive wear of some polyimides and their composites," Tribology International, vol. 24, no. 4, pp. 247-254, 1991.

[20] K. Friedrich and M. Cyffka, "On the wear of reinforced thermoplastics by different abrasive papers," Wear, vol. 103, no. 4, pp. 333-344, 1985.

[21] H. Voss and K. Friedrich, "Wear performance of a bulk liquid crystal polymer and its short-fibre composites," Tribology International, vol. 19, no. 3, pp. 145-156, 1986.

[22] S. Bahadur, D. Gong, and J. W. Anderegg, "The role of copper compounds as fillers in transfer film formation and wear of nylon," Wear, vol. 154, no. 2, pp. 207-223, 1992.

[23] S. Bahadur and G. Deli, "The transfer and wear of nylon and CuS-nylon composites: filler proportion and counterface characteristics," Wear, vol. 162-164, pp. 397-406, 1993.

[24] S. Bahadur and D. Tabor, "The wear of filled polytetrafluoroethylene," Wear, vol. 98, pp. 1-13, 1984.

[25] S. Bahadur and D. Gong, "The role of copper compounds as fillers in the transfer and wear behavior of polyetheretherketone," Wear, vol. 154, no. 1, pp. 151-165, 1992.

[26] S. Bahadur and A. Kapoor, "The effect of ZnF2, ZnS and PbS fillers on the tribological behavior of nylon 11," Wear, vol. 155, no. 1, pp. 49-61, 1992.

[27] S. Bahadur, D. Gong, and J. W. Anderegg, "Investigation of the influence of $\mathrm{CaS}, \mathrm{CaO}$ and $\mathrm{CaF}_{2}$ fillers on the transfer and wear of nylon by microscopy and XPS analysis," Wear, vol. 197, no. 1-2, pp. 271-279, 1996.

[28] B. N. Ravi Kumar, B. Suresha, and M. Venkataramareddy, "Effect of particulate fillers on mechanical and abrasive wear behaviour of polyamide 66/polypropylene nanocomposites," Materials and Design, vol. 30, no. 9, pp. 3852-3858, 2009.

[29] J. Bijwe, J. Indumathi, J. John Rajesh, and M. Fahim, "Friction and wear behavior of polyetherimide composites in various wear modes," Wear, vol. 249, no. 8, pp. 715-726, 2001.

[30] V. Pettarin, M. J. Churruca, D. Felhös, J. Karger-Kocsis, and P. M. Frontini, "Changes in tribological performance of high molecular weight high density polyethylene induced by the addition of molybdenum disulphide particles," Wear, vol. 269, no. 1-2, pp. 31-45, 2010.

[31] J. Tong, Y. Ma, and M. Jiang, "Effects of the wollastonite fiber modification on the sliding wear behavior of the UHMWPE composites," Wear, vol. 255, no. 1-6, pp. 734-741, 2003.

[32] H. Voss and K. Friedrich, "On the wear behaviour of short-fibrereinforced peek composites," Wear, vol. 116, no. 1, pp. 1-18, 1987.

[33] C. Douglas Montgomery, Design and Analysis of Experiments, John Wiley \& Sons, New York, NY, USA, 5th edition, 2001.

[34] M. H. Cho, S. Bahadur, and A. K. Pogosian, "Friction and wear studies using Taguchi method on polyphenylene sulfide filled with a complex mixture of $\mathrm{MoS}_{2}, \mathrm{Al}_{2} \mathrm{O}_{3}$, and other compounds," Wear, vol. 258, no. 11-12, pp. 1825-1835, 2005.

[35] K. M. Subbaya, B. Suresha, N. Rajendra, and Y. S. Varadarajan, "Grey-based Taguchi approach for wear assessment of SiC filled carbon-epoxy composites," Materials \& Design, vol. 41, pp. 124130, 2012.

[36] M. Sudheer, R. Prabhu, K. Raju, and T. Bhat, "Optimization of dry sliding wear performance of ceramic whisker filled epoxy composites using taguchi approach," Advances in Tribology, vol. 2012, Article ID 431903, 9 pages, 2012.

[37] B. N. Ramesh and B. Suresha, "Optimization of tribological parameters in abrasive wear mode of carbon-epoxy hybrid composites," Materials \& Design, vol. 59, pp. 38-49, 2014.
[38] G. Agarwal, A. Patnaik, and R. Kumar Sharma, "Parametric optimization of three-body abrasive wear behaviour of bidirectional and short Kevlar fiber reinforced epoxy composites," International Journal of Engineering Research and Applications, vol. 2, no. 6, pp. 1148-1167, 2012.

[39] N. Chand, A. Naik, and S. Neogi, "Three-body abrasive wear of short glass fibre polyester composite," Wear, vol. 242, no. 1-2, pp. 38-46, 2000.

[40] M. Jacob, B. Francis, S. Thomas, and K. T. Varughese, "Dynamical mechanical analysis of sisal/oil palm hybrid fiber-reinforced natural rubber composites," Polymer Composites, vol. 27, no. 6, pp. 671-680, 2006.

[41] G. Wu, J. Gu, and X. Zhao, "Preparation and dynamic mechanical properties of polyurethane-modified epoxy composites filled with functionalized fly ash particulates," Journal of Applied Polymer Science, vol. 105, no. 3, pp. 1118-1126, 2007.

[42] J. Bras, M. L. Hassan, C. Bruzesse, E. A. Hassan, N. A. El-Wakil, and A. Dufresne, "Mechanical, barrier, and biodegradability properties of bagasse cellulose whiskers reinforced natural rubber nanocomposites," Industrial Crops and Products, vol. 32, no. 3, pp. 627-633, 2010.

[43] S. Pattanawanidchai, P. Saeoui, and C. Sirisinha, "Influence of precipitated silica on dynamic mechanical properties and resistance to oil and thermal aging in CPE/NR blends," Journal of Applied Polymer Science, vol. 96, no. 6, pp. 2218-2224, 2005.

[44] S. G. Kuzak and A. Shanmugam, "Dynamic mechanical analysis of fiber-reinforced phenolics," Journal of Applied Polymer Science, vol. 73, pp. 649-658, 1999.

[45] N. Chand and S. Neogi, "Mechanism of material removal during three-body abrasion of FRP composite," Tribology Letters, vol. 4, no. 1, pp. 81-85, 1998.

[46] A. P. Harsha, U. S. Tewari, and B. Venkatraman, "Three-body abrasive wear behaviour of polyaryletherketone composites," Wear, vol. 254, no. 7-8, pp. 680-692, 2003.

[47] A. P. Harsha and U. S. Tewari, "Two-body and three-body abrasive wear behaviour of polyaryletherketone composites," Polymer Testing, vol. 22, no. 4, pp. 403-418, 2003.

[48] J. K. Lancaster, "Friction and wear," in Polymer Science: A Material Science Handbook, North-Holland, Amsterdam, The Netherlands, 1972.

[49] S. N. Ratner, I. I. Farberova, O. V. Radynkevich, and E. G. Lure, "Correlations between wear resistance and other mechanical properties," Soviet Plastics, vol. 7, pp. 37-45, 1964.

[50] S. R. Chauhan, A. Kumar, I. Singh, and P. Kumar, "Effect of fly ash content on friction and dry sliding wear behavior of glass fiber reinforced polymer composites-a Taguchi approach," Journal of Minerals and Materials Characterization and Engineering, vol. 9, no. 4, pp. 365-387, 2010.

[51] P. J. Ross, Taguchi Techniques for Quality Engineering, McGrawHill, New York, NY, USA, 2nd edition, 2001.

[52] K. R. Roy, A Primer on the Taguchi Method, Van Nostrand Reinhold, New York, NY, USA, 1990.

[53] A. Patnaik, A. Satapathy, M. Dwivedy, and S. Biswas, "Wear behavior of plant fiber (Pine-Bark) and cement kiln dustreinforced polyester composites using Taguchi experimental model," Journal of Composite Materials, vol. 44, no. 5, pp. 559$574,2010$. 

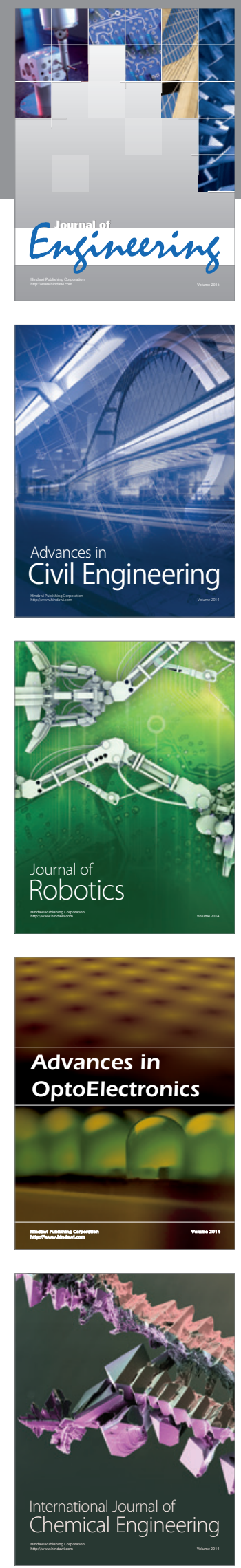

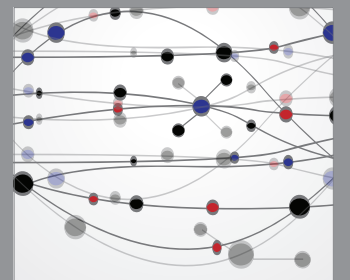

The Scientific World Journal
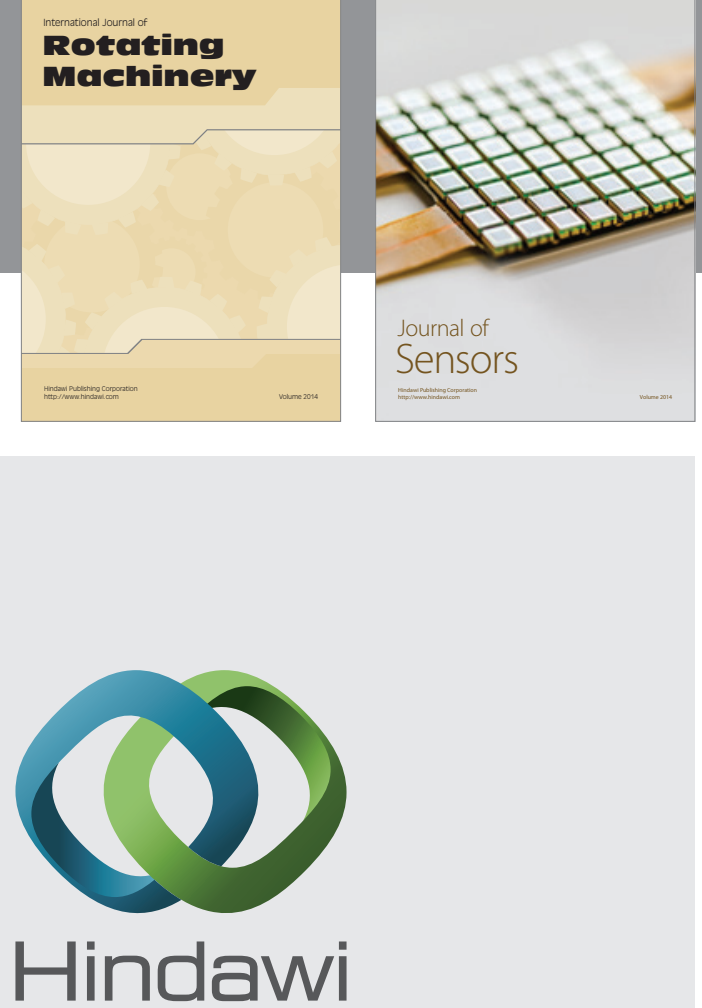

Submit your manuscripts at http://www.hindawi.com
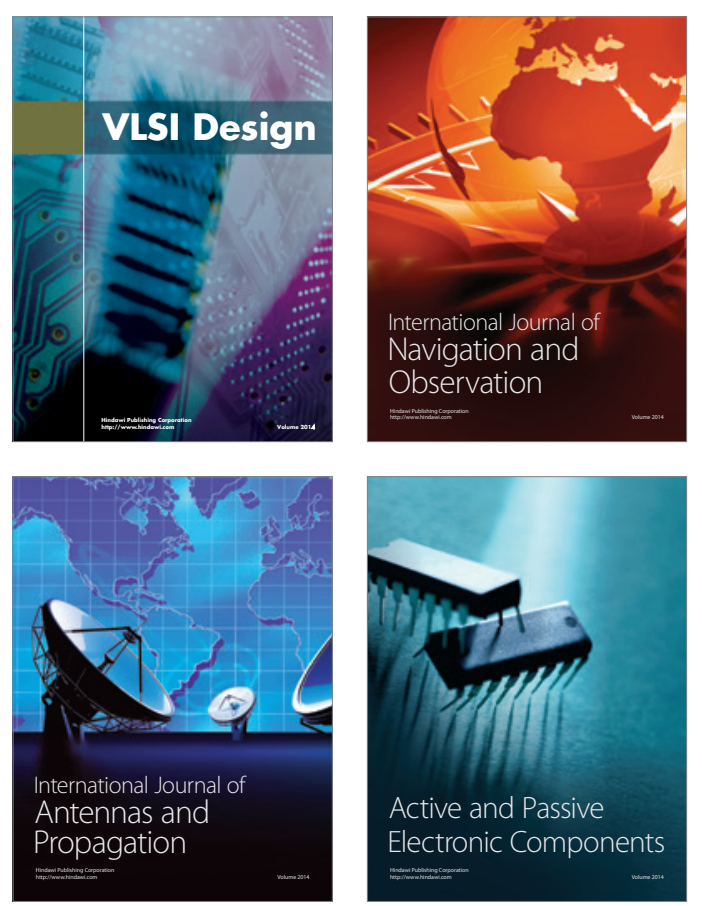
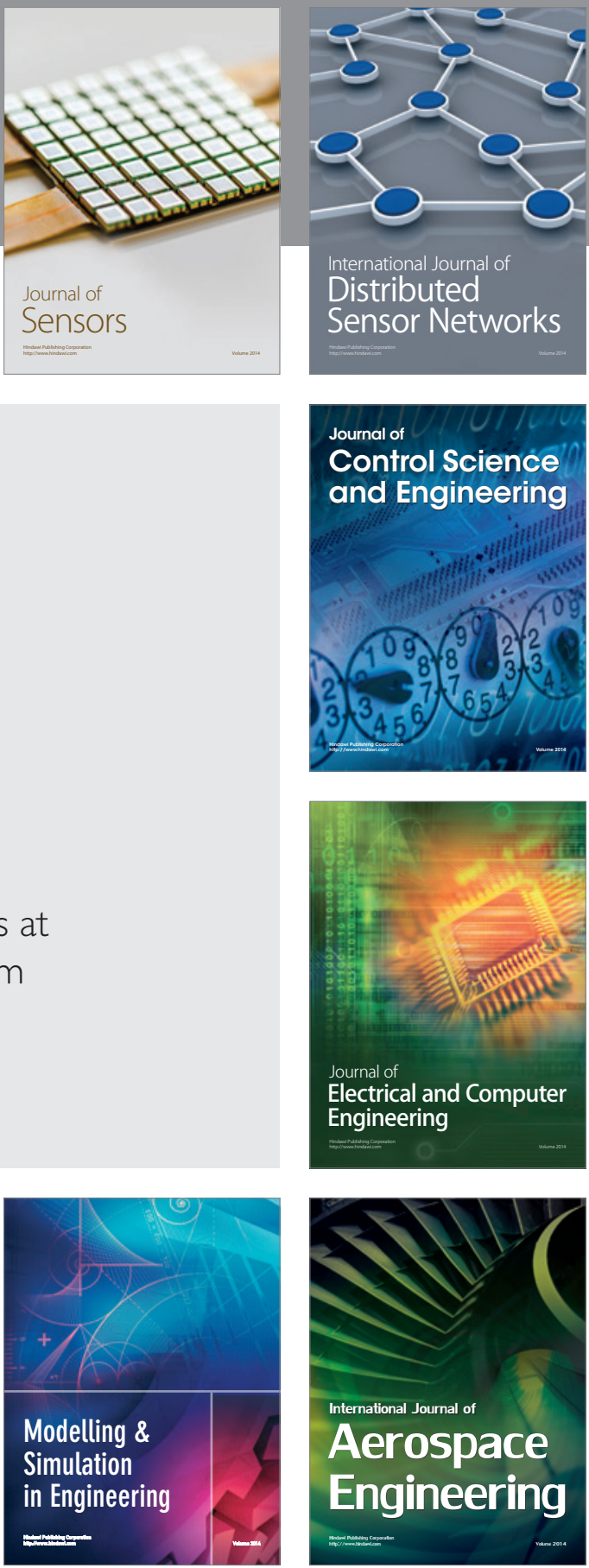

Journal of

Control Science

and Engineering
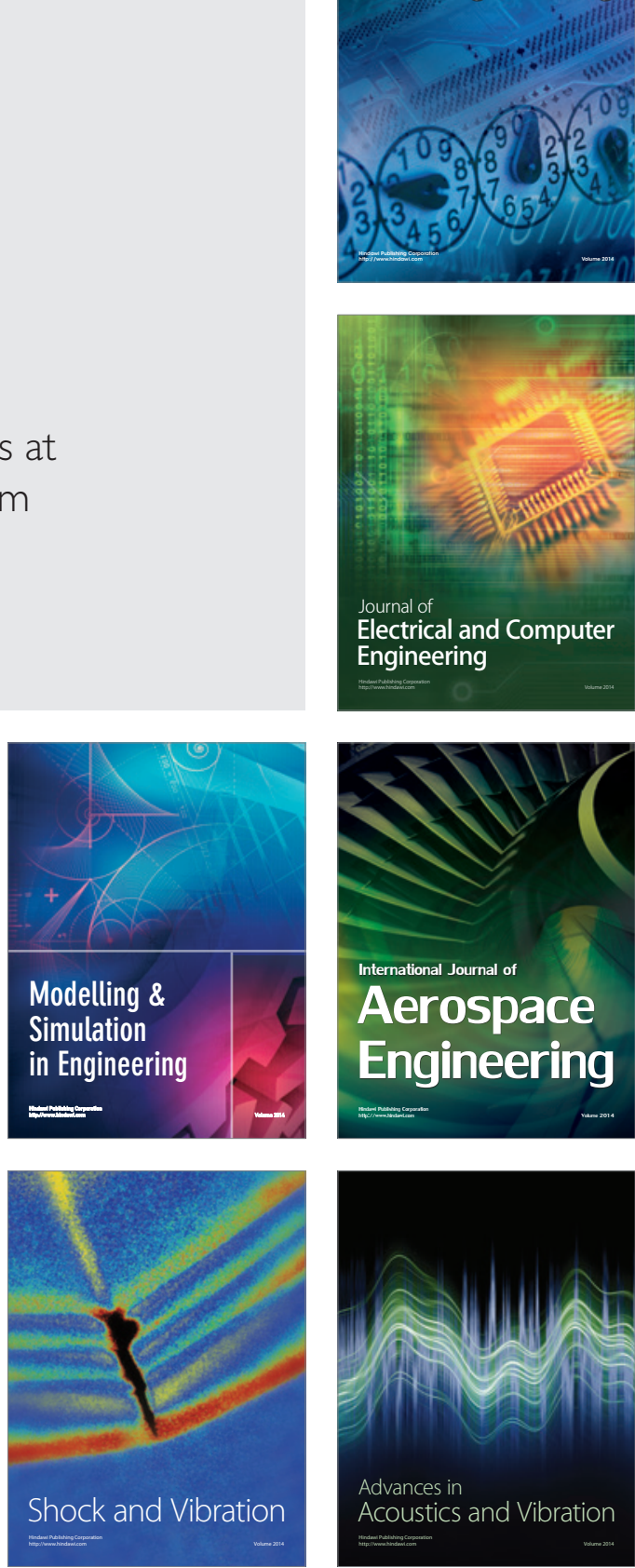